\title{
Efeito da calagem na lixiviação de imazethapyr e imazapyr em solo de cultivo de arroz irrigado
}

\author{
Effect of liming on imazethapyr and imazapyr leaching in rice paddy soil
}

\author{
João Paulo Refatti ${ }^{\mathrm{I}}$ Luis Antonio de Avila ${ }^{\mathrm{I}}$ Dirceu Agostinetto ${ }^{\mathrm{I}}$ Roberta Manica-Berto ${ }^{\mathrm{I}}$ \\ Angela Da Cas Bundt ${ }^{I}$ Diogo Balbé Elgueira ${ }^{\mathrm{I}}$
}

\section{RESUMO}

Os herbicidas do grupo das imidazolinonas são amplamente utilizados no cultivo de arroz irrigado para o controle das principais plantas daninhas. Esses herbicidas comportamse como ácidos ou bases fracas, dependendo do $\mathrm{pH}$, podendo, dessa forma, influenciar na sua lixiviação. O objetivo deste estudo foi avaliar o efeito da elevação do $\mathrm{pH}$, através da calagem, na lixiviação de imazethapyr e imazapyr em solo de cultivo de arroz irrigado. Foram coletadas amostras indeformadas de solo com pH natural próximo a 4,8 em uma lavoura de arroz irrigado sem histórico de aplicação de imidazolinonas. As colunas de solo foram coletadas utilizando-se um extrator e constituíram-se nas unidades experimentais da primeira fase do experimento. $O$ experimento foi conduzido em casa de vegetação, arranjado em esquema fatorial, sendo o fator A constituído por solo com $\mathrm{pH}$ natural e solo com calagem. $O$ fator $B$ foi constituído pelos herbicidas imazethapyr $e$ imazapyr (todos a $100 \mathrm{~g}$ i.a. ha $^{-1}$ ), aplicados sobre a superfície das colunas de solo. $O$ fator $C$ foi constituído das profundidades de amostragem (5 em 5cm). Os resultados mostram que a alteração do $\mathrm{pH}$ influencia na lixiviação dos herbicidas testados, quando aplicados em solo de cultivo de arroz irrigado. O solo calcareado apresenta maior lixiviação dos herbicidas imazapyr e imazethapyr.

Palavras-chave: percolação, calcário, poluição ambiental, imidazolinonas.

\section{ABSTRACT}

Imidazolinone herbicides are widely used in rice for the control of major weeds. These herbicides behave as weak acids or bases, depending on the $\mathrm{pH}$ which may affect leaching. The objective of this study was to evaluate the effect of liming on imazethapyr and imazapyr leaching. Undisturbed soil samples ( $\mathrm{pH} 4.8$ ) were collected in a rice paddy field without history imidazolinone application. The soil columns, that constituted the experiment units, were collected using a soil extractor constituting. The experiment was conducted in a greenhouse, arranged in a factorial design, begin the factor $A$ included of soil with natural $\mathrm{pH}$ and limed soil. Factor $B$ was included the herbicides imazethapyr and imazapyr (all at $100 \mathrm{~g}$ a.i. ha ${ }^{-1}$ ) applied to the surface of the soil columns. Factor $C$ included of sampling depths at the end of the experiment to evaluate leaching (5 by $5 \mathrm{~cm}$ ). The results showed that enhanced $\mathrm{pH}$ cause by liming affect herbicide leaching in rice paddy soil. Soil liming enhance imazethapyr and imazapic leaching.

Key words: percolation, lime, environmental pollution, imidazolinones.

\section{INTRODUÇÃO}

Os herbicidas do grupo químico das imidazolinonas são amplamente utilizados devido a fatores como seletividade a algumas culturas, eficiência no controle de plantas daninhas e atividade residual no solo (SHAW \& WIXSON,1991; LOUX \& REESE,1993), dentre outros. Esses são absorvidos tanto pelas folhas quanto pelas raízes, inibindo a síntese de acetolactate synthase (ALS) ou acetohydroxyacid synthase (AHAS), responsável pela biossíntese de aminoácidos de cadeia ramificada em plantas. Esses herbicidas podem ser aplicados em pré ou pós-emergência (STEELE et al., 2002; OTTIS et al., 2003), como herbicidas seletivos para o controle de um amplo espectro de plantas daninhas monocotiledôneas e dicotiledôneas em culturas de grande importância, como soja, arroz e cana-de-açúcar. Também podem ser utilizados como herbicidas não seletivos em áreas não agrícolas, devido à sua elevada persistência no solo, bem como na silvicultura e pastagens (MASTERS et al., 1996).

IUniversidade Federal de Pelotas (UFPel), 96160-000, Pelotas, RS, Brasil. E-mail: laavilabr@gmail.com. Autor para correspondência. 
$\mathrm{Na}$ cultura do arroz irrigado, o desenvolvimento da tecnologia Clearfield ${ }^{\circledR}$ fez com que esses herbicidas passassem a ser utilizados com maior frequência nas áreas de relevo plano, onde é cultivado o arroz irrigado. Essa tecnologia combina cultivares tolerantes/resistentes com herbicidas do grupo químico das imidazolinonas, formulados isoladamente ou em misturas, visando ao controle das principais plantas daninhas da cultura.

As moléculas dos herbicidas imidazolinonas apresentam um comportamento anfótero, devido à presença de grupos funcionais carboxílicos (ácido) e amino (básicos). Essa característica confere a esses herbicidas a capacidade de agirem como ácidos ou bases fracas, dependendo do $\mathrm{pH}$ do meio em que se encontram (PUSINO et al., 1997). Com isso, dependendo do coeficiente de ionização (pKa) do herbicida e do $\mathrm{pH}$ do ambiente considerado, as moléculas dos herbicidas podem apresentarem-se mais ou menos disponíveis na solução do solo. $\mathrm{O}$ pKa representa o pH no qual as moléculas encontram-se $50 \%$ na forma associada ou neutra $(\mathrm{COOH})$ e $50 \%$ na forma dissociada ou iônica $\left(\mathrm{COO}^{-}\right)$. Com isso, quando o $\mathrm{pH}$ do solo for maior que o pKa do herbicida, suas moléculas apresentam-se em sua maior parte na forma aniônica $\left(\mathrm{COO}^{-}\right)$, porémhá a predominânciada forma associada $(\mathrm{COOH})$, quando o $\mathrm{pH}$ do solo é mais baixo que o pKa do herbicida. Os valores de $\mathrm{pKa}$ dos herbicidas imidazolinonas variam entre 1,3 e 3,9, podendo, na mesma molécula, existirem um ou mais $\mathrm{pKa}$. O herbicida imazethapyr, por exemplo, apresenta dois pKa $(3,9$ e 2,1) assim como o imazapyr (3,6 e 1,9), já o imazapic apresenta apenas um $(3,9)$ (SENSEMAN, 2007). Quanto maior for o $\mathrm{pKa}$ do herbicida, menor será seu caráter ácido e menor a sua capacidade de encontrar-se na forma iônica.

Em solos com pH elevado, a sorção desses herbicidas é reduzida, devido à predominância de moléculas dissociadas ( $\left.\mathrm{COO}^{-}\right)$as quais são repelidas pelas cargas negativas do solo, permanecendo mais biodisponível na solução do solo. Por outro lado, em solos com $\mathrm{pH}$ baixo, o número de moléculas associadas $(\mathrm{COOH})$ é maior, aumentando a sorção desses herbicidas à matriz do solo (MADANI et al., 2003; OLIVEIRA et al., 2004). Devido aos baixos valores de $\mathrm{pKa}$ das imidazolinonas, esses herbicidas têm sido considerados de elevado potencial de lixiviação (REGITANO et al., 2002), podendo causar contaminação de águas subterrâneas. Em lavouras de arroz irrigado, o elevado teor de água no solo aumenta a disponibilidade destes herbicidas (AVILA et al., 2005), podendo aumentar ainda mais o deslocamento deles no perfil do solo.
Quando o valor do $\mathrm{pH}$ da solução do solo está próximo ao pKa do herbicida, pequenas variações no $\mathrm{pH}$ provocam grandes alterações nas proporções de moléculas associadas e dissociadas, influenciando a disponibilidade desses herbicida na solução do solo. Com isso, a alteração do $\mathrm{pH}$ do solo, através de práticas de manejo, como a calagem e, no caso de lavouras de arroz irrigado, o estabelecimento de lâmina de água, resultando na auto calagem, podem aumentar a lixiviação e consequentemente os riscos de contaminação.

A expansão do cultivo de soja em áreas de cultivo de arroz irrigado, nos últimos anos, como alternativa de rotação de cultura, tem incentivado a elevação do $\mathrm{pH}$ desses solos através da calagem. A elevação do $\mathrm{pH}$ para a cultura de arroz irrigado não tem demonstrado aumento significativo na produção de grãos (MORAES \& DYNIA, 1992), principalmente, devido ao fenômeno da auto calagem, que ocorre naturalmente após o estabelecimento da lâmina de água. Entretanto, o cultivo de soja, na mesma área, faz com que haja a necessidade de correção da acidez, visto que proporciona considerável aumento na produção final dessa cultura (SÁVIO et al., 2011).

Nesse contexto, solos com diferentes valores de $\mathrm{pH}$ podem oferecer diferentes condições de lixiviação para os herbicidas imidazolinonas. A influência do $\mathrm{pH}$ dos solos nas formas em que as moléculas desses herbicidas se encontram na natureza podem sugerir diferentes formas de manejos, a fim de diminuir os riscos de contaminação ambiental. Dessa forma, o objetivo deste estudo foi avaliar o efeito da elevação do pH, através da calagem, na lixiviação de imazethapyr e imazapyr em solo de cultivo de arroz irrigado.

\section{MATERIAL E MÉTODOS}

O experimento foi conduzido em casa de vegetação no ano agrícola 2011/2012, sendo realizado em três etapas. Na primeira etapa, foram coletadas colunas de solo em uma lavoura com pH natural próximo a 4,8, na cidade de Faxinal do Soturno, localizada na depressão central do Estado do Rio Grande do Sul (29³2'59,01’S, 53²9’27,42”O). A coleta foi realizada no mês de setembro em área de cultivo de arroz irrigado sem histórico de aplicação de imidazolinonas. As amostras foram coletadas com o auxílio de um extrator de solo (Figura 1A), constituído por um cilindro de metal, no qual foram inseridos tubos de PVC até a profundidade de $30 \mathrm{~cm}$, sem que houvesse a desestruturação das camadas. Os tubos possuíam $40 \mathrm{~cm}$ de comprimento por $15 \mathrm{~cm}$ 
de diâmetro, sendo, após a coleta, vedados com uma tampa (CAP-PVC) em sua base inferior (Figura 1B). Os tubos, juntamente com as colunas de solo, constituíram-se nas unidades experimentais da primeira etapa do experimento. Para o estabelecimento de uma lâmina de água, foram reservados $10 \mathrm{~cm}$ de borda livre em cada unidade experimental. O solo predominante no local de coleta foi classificado como Planossolo Háplico. Em seguida, após a coleta, foi realizada a calagem e incorporação até $15 \mathrm{~cm}$ de profundidade em metade das colunas de solo. Nas demais unidades experimentais, o solo foi apenas revolvido até a mesma profundidade para manter as mesmas condições em todas as unidades experimentais. A quantidade de calcário utilizada foi estimada pelo índice SMP para elevar o pH a 6,0. O calcário utilizado foi o filler (PRNT $>90 \%$ ), por apresentar rápida reação no solo. Além disso, o solo das unidades experimentais foi irrigado semanalmente para acelerar o efeito do calcário.

Asegunda etapa do experimento foi iniciada 30 dias após a calagem e constituiu-se da aplicação dos tratamentos herbicidas. Os herbicidas utilizados foram: imazethapyr (100g i.a. ha-1) e imazapyr $\left(100 \mathrm{~g}\right.$ i.a. ha $\left.{ }^{-1}\right)$ e mais um tratamento testemunha, sem aplicação de herbicidas. Esses herbicidas foram escolhidos por apresentarem a maior diferença de pKa entre os imidazolinonas registrados para o uso em arroz irrigado. Os herbicidas foram aplicados com o auxílio de um borrifador, utilizando-se um volume de calda de $10 \mathrm{~mL}$ por unidade experimental. Para que não houvesse a contaminação das bordas internas superiores e posterior escorrimento pelas laterais, durante a aplicação dos tratamentos, foi utilizado um cano PVC de menor diâmetro no interior da parte superior dos tubos que continha o solo.

Um dia após a aplicação dos tratamentos, foi estabelecida uma lâmina de água constante de seis centímetros de altura acima do nível do solo por 60 dias, simulando as condições normais de cultivo. Em lavoura comercial, o período em que o solo fica com lâmina é de aproximadamente 80 dias, não sendo adotado esse intervalo de tempo nesse experimento devido à necessidade de condições climáticas ideais para a realização do bioensaio. Após esse período, as colunas de solo foram cortadas longitudinalmente e o solo removido para a condução do bioensaio.

A terceira etapa do experimento consistiu na condução de um bioensaio com o solo retirado das unidades experimentais onde foram aplicados os tratamentos na segunda etapa. Para isso, as colunas de solo foram seccionadas de cinco em cinco centímetros de profundidade $(0-5,5-10,10-15,15-20,20-25$ e 25-30 cm). Posteriormente, o solo de cada camada foi destorroado e colocados $400 \mathrm{~g}$ deste em potes de $500 \mathrm{ml}$, devidamente identificados. Após isso, cada solo armazenado nos potes foi adubado com $300 \mathrm{~kg}$ $\mathrm{ha}^{-1}$ da fórmula 05-20-20 $\left(\mathrm{N}-\mathrm{P}_{2} \mathrm{O}_{5}-\mathrm{K}_{2} \mathrm{O}\right)$ e procedeu-

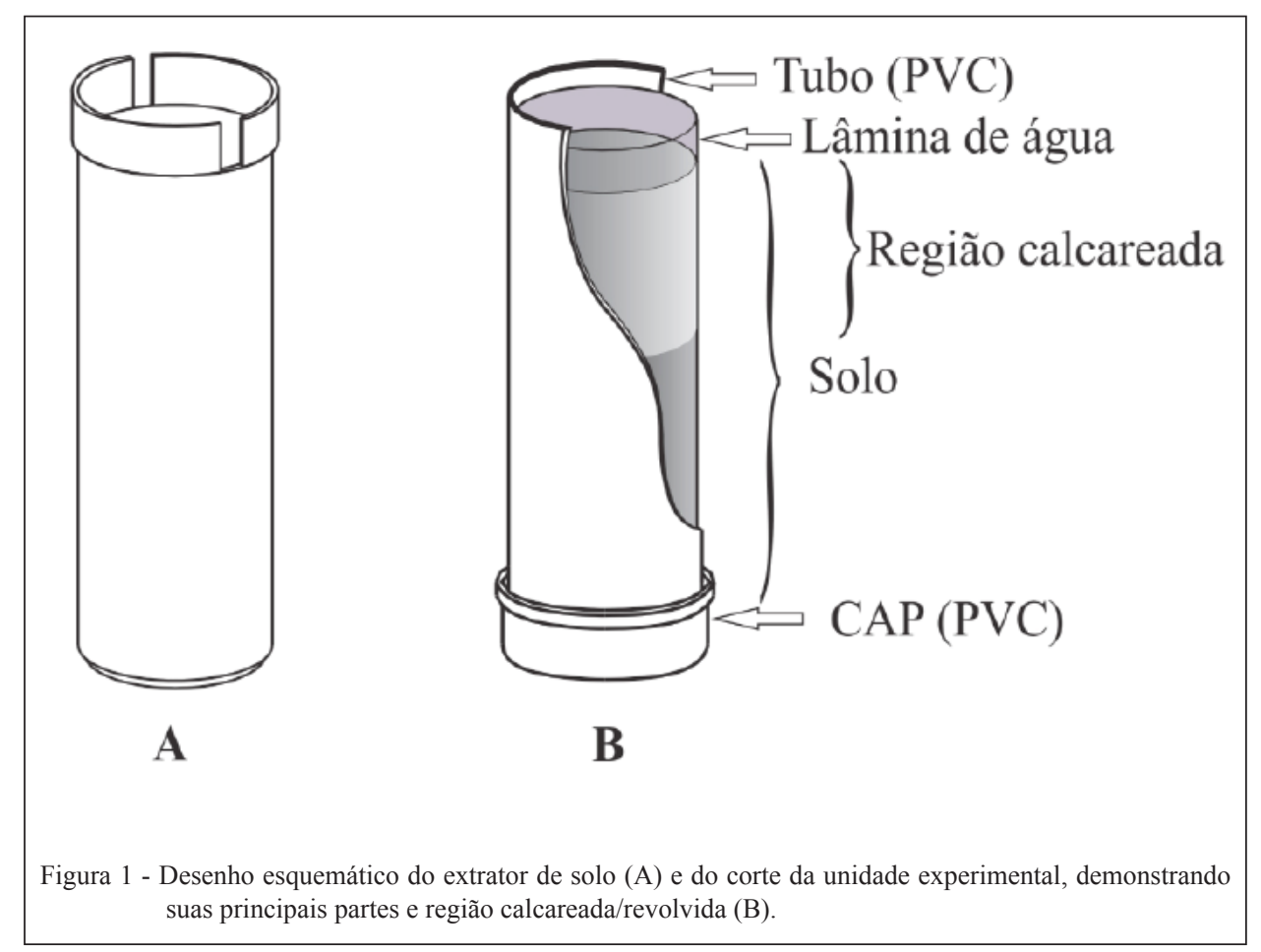

Ciência Rural, v.44, n.6, jun, 2014. 
se à semeadura com a cultivar de arroz IRGA 417, sensível ao grupo químico das imidazolinonas. Após 20 dias da semeadura, aplicou-se nitrogênio na forma de ureia e os potes foram mantidos com aproximadamente dois centímetros de lâmina de água até o fim da condução do experimento. O bioensaio foi conduzido em câmara de crescimento com temperatura controlada. Foram utilizadas três repetições de cada tratamento. Para análise, as camadas de solo foram consideradas como fator C. Antes da realização do bioensaio, foram coletados aproximadamente $300 \mathrm{~g}$ de solo de todas as camadas para análises físico-químicas (Tabela 1). Foi escolhido o método de avaliação através de bioensaio devido à diversos fatores, como sensibilidade, possibilidade de reprodução dos resultados, economia e eficiência.

As variáveis avaliadas foram: toxicidade dos herbicidas às plantas de arroz e estatura de planta. A avaliação da toxicidade dos herbicidas às plantas de arroz aos sete, 14, 21 e 28 dias após a emergência (DAE) foi realizada visualmente, atribuindo-se notas de 0 a 100\%. Nessa escala, zero corresponde à ausência de sintomas de fitotoxicidade e $100 \%$ corresponde à morte das plantas de arroz (GAZZIERO et al., 1995). A estatura foi determinada com o auxílio de régua milimetrada aos sete, 14, 21 e 28DAE, medindo-se, no colmo principal, a distância do nível do solo até a extremidade da última folha com colar formado. A lixiviação foi estimada através de bioensaio, utilizando as avaliações de fitotoxicidade observada e a redução de estatura em relação às plantas testemunhas, calculada aos 21DAE. As avaliações aos sete, 14 e 28DAE não foram apresentadas, pois possuíam menor diferenciação entre as plantas. As duas primeiras datas de avaliação, devido ao não estabelecimento da lâmina de irrigação, a qual disponibiliza mais os herbicidas no solo, e causa maior fitotoxicidade nas plantas e aos 28DAE devido à recuperação das mesmas.
Os dados foram analisados quanto à normalidade pelo teste de Shapiro-Wilk e à homocedasticidade pelo teste de Levene, posteriormente, foram submetidos à análise de variância $(p \leq 0,05)$. Em caso de significância, as médias foram comparadas pelo teste de Tukey $(\mathrm{p} \leq 0,05)$ e por intervalos de confiança $(95 \%)$.

\section{RESULTADOS E DISCUSSÃO}

Houve interação significativa $(p \leq 0,05)$ entre manejos de solo (com calagem e sem calagem), tratamentos herbicidas e camadas de solo para todas as variáveis analisadas.

Os resultados demonstram que houve lixiviação dos herbicidas imazethapyr e imazapyr, sendo seus efeitos fitotóxicos detectados até a profundidade de corte de $15-20 \mathrm{~cm}$ (Figura 2A) e de redução de estatura em relação à testemunha até a profundidade de corte de 25-30 (Figura 2B). Os efeitos da presença dos herbicidas foram observados com maior intensidade nas camadas superficiais de todos os tratamentos, independente do manejo adotado. $\mathrm{O}$ manejo de solo sem calagem, onde o $\mathrm{pH}$ era menor, apresentou, em geral, menor lixiviação tanto para o herbicida imazethapyr como para o imazapyr. Esses resultados corroboram os encontrados na literatura quanto à influência do $\mathrm{pH}$ do meio na lixiviação de imidazolinonas. MONQUERO et al. (2008), testando diferentes pHs (4,7 e 6), constataram ligeiro aumento da lixiviação na condição de solo mais alcalino. Tais resultados ocorrem devido à capacidade que esses herbicidas possuem de se ionizarem, alterando sua interação com as partículas de solo. Com isso, quando o $\mathrm{pH}$ do solo se aproxima da neutralidade, passa a predominar a forma dissociada (aniônica) desses herbicidas (MANGELS, 1991; AICHELE \& PENNER, 2005), diminuindo a força de atração

Tabela 1 - Tabela com os dados de pH em água, teor de argila, matéria orgânica (MO), saturação por alumínio (S. Al), saturação por bases (S. B) e capacidade de troca de cátions (CTC) efetiva para o solo de Faxinal do Soturno - RS.

\begin{tabular}{|c|c|c|c|c|c|c|c|c|}
\hline \multirow{2}{*}{$\begin{array}{l}\text { Camadas } \\
(\mathrm{cm})\end{array}$} & \multicolumn{2}{|c|}{-----------pH } & Argila & $\mathrm{MO}$ & S. Al & S. B & \multicolumn{2}{|c|}{ 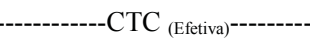 } \\
\hline & Natural $^{1}$ & $30 \operatorname{dias}^{2}$ & -------- & ------- & -------- & -------- & Natural $^{1}$ & $30 \operatorname{dias}^{2}$ \\
\hline $0-5$ & 4,8 & 6,1 & 14 & 1,8 & 11,7 & 54,7 & 7,6 & 8,4 \\
\hline $5-10$ & 4,9 & 5,1 & 14 & 1,3 & 16,9 & 50,1 & 4,9 & 4,9 \\
\hline $10-15$ & 4,7 & 4,8 & 15 & 1,2 & 15,9 & 54,8 & 4,7 & 4,6 \\
\hline $15-20$ & 4,8 & 4,8 & 15 & 1,2 & 15,5 & 58,7 & 4,8 & 6,0 \\
\hline $20-25$ & 4,7 & 5,0 & 15 & 1,2 & 12,1 & 57 & 6,8 & 6,1 \\
\hline $25-30$ & 5,1 & 5,0 & 16 & 1,1 & 5,5 & 66,4 & 6,7 & 7,2 \\
\hline
\end{tabular}

${ }^{1}$ Valor antes da calagem;

${ }^{2}$ Valor 30 dias após a calagem. 


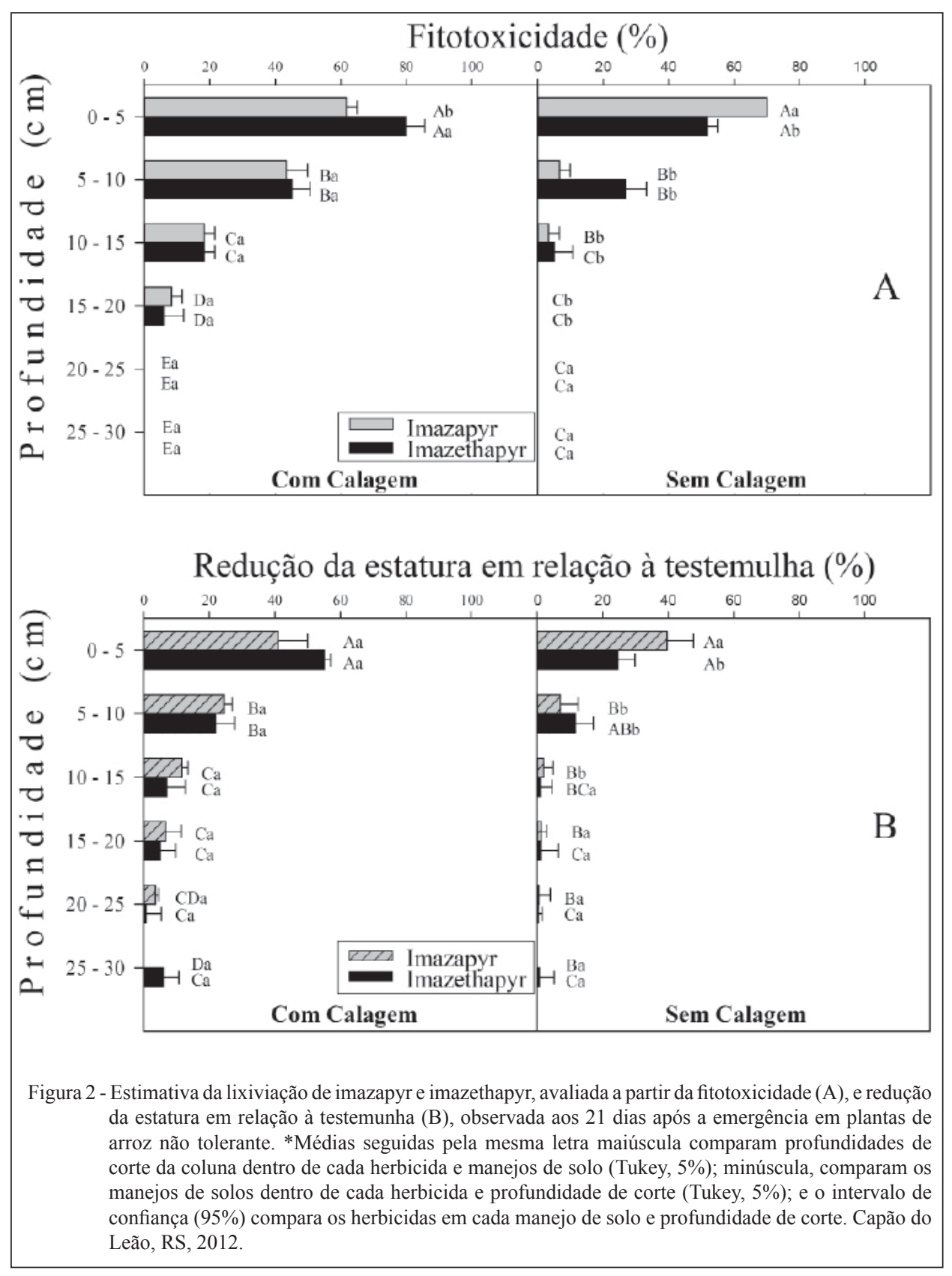

entre as moléculas das imidazolinonas e as cargas predominantes na matriz do solo. Consequentemente, há menor sorção desses herbicidas, causando maior lixiviação no solo. A pequena diferença nos resultados, entre os dois manejos, pode estar relacionada com a pequena variação de $\mathrm{pH}$ entre os dois tratamentos, aliado à pequena diferença entre os pKa dos dois herbicidas, 3,6 e 3,9 para imazapyr e imazethapyr, respectivamente. Além das características das moléculas (SENSEMAN et al., 2007) e pH (LOUX \& REESE, 1993), a diferença na lixiviação, observada a partir da fitotoxicidade, pode estar relacionada com o teor de matéria orgânica (STOUGAARD et al., 1990), textura (LOUX \& REESE, 1993), manejo (KRAEMER et al., 2009) e umidade do solo (BAUGHMAN \& SHAW, 1996). Com isso, a dinâmica de um herbicida no ambiente deve ser tratada considerando-se as características de cada local, assim como das moléculas desses produtos.

Quanto à diferença de estatura em relação à testemunha, os resultados obtidos mostram semelhança com os encontrados para a fitotoxicidade 
(Figura 2B). Tanto para o solo com calagem quanto sem, foram detectadas variações na estatura em relação à testemunha, até a camada de $25-30 \mathrm{~cm}$. A maior redução de estatura em relação à testemunha, assim como a fitotoxicidade, ocorreu nas camadas superiores do perfil do solo, o que demonstra que, apesar de haver lixiviação dos herbicidas nos dois manejos, a maior concentração deles localiza-se nessas camadas. Comparando os diferentes manejos, houve maior redução da estatura em relação à testemunha no solo calcareado, o que corrobora os dados obtidos de fitotoxicidade. Nas camadas mais inferiores, foi observada diminuição da estatura em relação à testemunha, entretanto essa redução pode não ter sido causada pela ação dos herbicidas e sim pela utilização de escala diferente da de fitotoxicidade para a medição das plantas, a qual considera pequenas variações, quando comparada com a avaliação de fitotoxicidade.

Grande parte do volume dos produtos químicos aplicados em uma lavoura, dentre eles os herbicidas, tem como destino final o solo, podendo causar contaminação. Contudo, os resultados obtidos neste trabalho auxiliam no melhor entendimento da dinâmica dos herbicidas imazapyr e imazethapyr quanto às condições de $\mathrm{pH}$ do solo em que se encontram. Porém, para um eficiente uso desses herbicidas, devemos considerar as diversas variáveis relacionadas ao solo e ao ambiente. Aliada a isso, existe a necessidade de corrigir o $\mathrm{pH}$ do solo, para obtenção de maior produtividade, o que exige maior atenção quanto ao uso de herbicidas ionizáveis como as imidazolinonas. Tendo em vista a semelhança entre as moléculas desse grupo químico e as peculiaridades de cada local de aplicação, é possível generalizar, com algumas restrições, o comportamento das demais imidazolinonas utilizadas no sistema Clearfield ${ }^{\circledR}$.

Entretanto, devem ser tomados alguns cuidados quando da aplicação de imidazolinonas em áreas com $\mathrm{pH}$ elevado. Na quase totalidade das recomendações de herbicidas, não são consideradas as condições de cada local, como o $\mathrm{pH}$, podendo gerar graves problemas de contaminação do meio ambiente. STOUGAARD et al. (1990) encontraram maior capacidade de absorção de princípios ativos aos sorbentes do solo quando estes apresentavam $\mathrm{pH}$ ácido e com maior teor de matéria orgânica e argila. Corroborando esses resultados, WEHTJE et al. (1987) mostram, em seus resultados, maior mobilidade do imazapyr em solos argilosos e, também, que essa mobilidade diminuiu com a redução da umidade e do $\mathrm{pH}$ do solo. Contudo, podese notar que existem diversos fatores, além do $\mathrm{pH}$, que influenciam na lixiviação de imidazolinonas. Com isso, divergências entre os resultados de lixiviação encontradas na literatura podem estar relacionadas com fatores ligados aos sítios de adsorção do solo, tais como matéria orgânica e características mineralógicas e/ou com a própria degradação do herbicida no solo.

Entretanto, com os resultados obtidos neste experimento, é possível concluir que a elevação do $\mathrm{pH}$, através da calagem, aumenta a lixiviação dos herbicidas imazapyr e imazethapyr em solo de cultivo de arroz irrigado.

\section{AGRADECIMENTOS}

À Universidade Federal de Pelotas pela disponibilidade de sua estrutura e viabilização das pesquisas realizadas. À Coordenação de Aperfeiçoamento de Pessoal de Nível Superior (CAPES) pelo auxílio financeiro, ao Conselho Nacional de Desenvolvimento Científico e Tecnológico (CNPq) pela bolsa de produtividade em pesquisa do segundo autor. À CAPES pela bolsa de mestrado do primeiro autor e pelos recurso financeiros vinculados a bolsa do quarto autor (PROJETO DE PESQUISA - No 028423/2009 - MEC/CAPES - Programa Nacional de PósDoutorado - PNPD/2009).

\section{REFERÊNCIAS}

AICHELE, T.M.; PENNER, D. Adsorption, desorption, and degradation of imidazolinones in soil. Weed Technology, v.19, n.1, p.154-159, 2005.

AVILA, L.A. et al. Efeito da umidade do solo na sorção e disponibilidade de imazetapir em três solos. In:CONGRESSO BRASILEIRO DE ARROZ IRRIGADO, 4.; REUNIÃO DA CULTURA DO ARROZ IRRIGADO, 26., 2005, Santa Maria, RS. Anais... Santa Maria: UFSM, 2005. p.190-193.

BAUGHMAN, T.A.; SHAW, D.R. Effect of wetting/drying cycles on dissipation patterns of bioavailable imazaquin. Weed Science, v.44, n.2, p.380-382, 1996. Disponível em: <http://pubs.acs. org/doi/full/10.1021/jf052214b>. Acesso em: 20 dez. 2012. doi: $10.1021 / \mathrm{jf0} 2214 \mathrm{~b}$.

GAZZIERO, D.L.P. et al. Procedimentos para instalação, avaliação e análise de experimentos com herbicidas. Londrina: Sociedade Brasileira da Ciência de Plantas Daninhas, 1995. 42p.

KRAEMER, A.F. et al. Lixiviação do imazethapyr em solo de várzea sob dois sistemas de manejo. Ciência Rural, v.39, n.6, p.1660-1666, 2009. Disponível em: <http://www.scielo.br/scielo. php?script $=$ sci_arttext\&pid=S0103-84782009000600005\&lng $=$ pt\&nrm=iso $>$. Acesso em: 20 dez. 2012. doi: 10.1590/S010384782009005000119

LOUX, M.M.; REESE, K. Effect of soil type and $\mathrm{pH}$ on persistence and carryover of imidazolinones herbicides. Weed Technology, v.7, n.2, p.452-458, 1993.

MADANI, M.E. et al. pH effect and kinetic studies of the binding behaviour of imazethapyr herbicide on some Moroccan soils. Fresenius Environmental Bulletin, v.12, p.1114-1119, 2003. 
]MANGELS, G. Imazethapyr herbicides.In: SHANER, D.; CONNOR, S. (Eds.). The imidazolinones herbicides. Boca Raton: CRC, 1991. p.191-209.

MASTERS, R.A et al. Imidazolinone herbicides improve restoration of great plains grasslands. Weed Technology, v.10, p.392-403, 1996.

MONQUERO, P.A. et al. Potencial de lixiviação de herbicidas no solo submetidos a diferentes simulações de precipitação. Planta Daninha, v.26, n.2, p.403-409, 2008.

MORAES, J.F.V.; DYNIA, J.F. Alterações nas características químicas e físico-químicas de um solo Gley Pouco Húmico sob inundação e após a drenagem. Pesquisa Agropecuária Brasileira, v.27, n.2, p.225-235, 1992.

OLIVEIRA, M.F. et al. Sorção do herbicida imazaquin em Latossolo sob plantio direto e convencional. Pesquisa Agropecuária Brasileira, v.39, n.8, p.787-793, 2004.

OTTIS, B.V. et al. Imazethapyr application methods and sequences for imidazolinone-tolerant rice (Oryza sativa). Weed Technology, v.17, n.3, p.526-533, 2003.

PUSINO, A. et al. Adsorption and desorption of imazapyr by soil Journal Agricultural Food Chemistry, v.45, n.3, p.1012-1016, 1997.
REGITANO, B. et al. Imazaquin mobility in tropical soils in relation to soil moisture and rainfall timing. Weed Research, v.41, n.4, p.42-271, 2002.

SÁVIO, F.L. et al. Calagem e gessagem na nutrição e produção de soja em solo com pastagem degradada. Revista Agrotecnologia, v.2, n.1, p.19-31, 2011 .

SENSEMAN, S.A. Herbicide handbook. Lawrence: Weed Science Society of America, 2007. 458p.

SHAW, D.; WIXSON, M. Post emergence combinations of imazaquin or imazethapyr with AC 263,222 for weed control in soybean (Glycine max). Weed Science, v.39, p.644-649, 1991.

STEELE, G.L. et al. Control of red rice (Oryza sativa) in imidazolinone-tolerant rice (O. sativa). Weed Technology, v.16, n.3, p.627-630, 2002.

STOUGAARD, R.N. et al. Effect of soil type and $\mathrm{pH}$ on adsorption, mobility and efficacy of imazaquin and imazethapyr. Weed Science, v.36, n.1, p.67-73, 1990.

WEHTJE, G. et al. Sorption and mobility of sulfometuron and imazapyr in five Alabama soils. Weed Science, v.35, n.6, p.858864, 1987. 